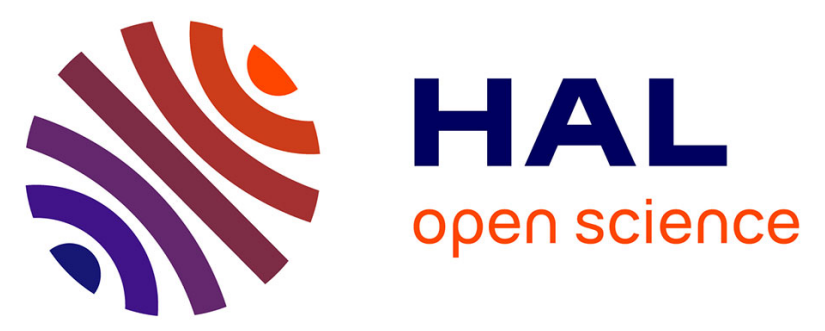

\title{
Au-NPs/ZnO Single Nanowire Nanosensors for Health Care Applications
}

Vasile Postica, Heather Cavers, Rainer Adelung, Thierry Pauporté, Lee Chow, Oleg Lupan

\section{- To cite this version:}

Vasile Postica, Heather Cavers, Rainer Adelung, Thierry Pauporté, Lee Chow, et al.. Au-NPs/ZnO Single Nanowire Nanosensors for Health Care Applications. 2020 International Conference on e-Health and Bioengineering (EHB), Oct 2020, Iasi, France. pp.1-4, 10.1109/EHB50910.2020.9280164 . hal03367275

\section{HAL Id: hal-03367275 \\ https://hal.science/hal-03367275}

Submitted on 6 Oct 2021

HAL is a multi-disciplinary open access archive for the deposit and dissemination of scientific research documents, whether they are published or not. The documents may come from teaching and research institutions in France or abroad, or from public or private research centers.
L'archive ouverte pluridisciplinaire HAL, est destinée au dépôt et à la diffusion de documents scientifiques de niveau recherche, publiés ou non, émanant des établissements d'enseignement et de recherche français ou étrangers, des laboratoires publics ou privés. 


\title{
Au-NPs/ZnO single nanowire nanosensors for health care applications
}

\author{
Vasile Postica ${ }^{1}$, Heather Cavers ${ }^{2}$, Rainer Adelung ${ }^{2}$, Thierry Pauporté ${ }^{3}$, Lee Chow ${ }^{4}$, Oleg Lupan ${ }^{1,2,3,4}$ \\ Affiliation 1: Center for Nanotechnology and Nanosensors, Technical University of Moldova, 168 Stefan cel Mare Av., MD-2004 \\ Chisinau, Republic of Moldova, oleg.lupan@mib.utm.md \\ Affiliation 2: Functional Nanomaterials, Institute for Materials Science, Faculty of Engineering, Kiel University, Kaiserstr. 2, D- \\ 24143, Kiel, Germany, ra@tf.uni-kiel.de \\ Affiliation 3: Institut de Recherche de Chimie Paris-IRCP, Chimie ParisTech, PSL Université, rue Pierre et Marie Curie 11, \\ 75231 Paris Cedex 05, France, thierry.pauporte@chimieparistech.psl.eu \\ Affiliation 4: Department of Physics, University of Central Florida, 4111 Libra Drive, Orlando, FL, 32816-2385USAFrance.
}

\begin{abstract}
Herein, the room temperature gas sensing properties of a device fabricatedbased on an individual gold nanoparticles (AuNPs)-functionalized zinc oxide nanowire $(\mathrm{ZnO} \mathrm{NW})$ is reported. The $\mathrm{Au}-\mathrm{NPs} / \mathrm{ZnO}$ nanowires were depositedusing theelectrochemical approachin a classical three-electrode electrochemical cell. The dual beam focused ion beam/scanning electron microscopy (FIB/SEM) was usedto integrate the singlenanostructuresinto gas sensing nanodevices.The results are promising for futureapplications in monitoring H2gas for health care applications and clinical breath analysis.
\end{abstract}

Keywords—nanosensors; hydrogen gas sensor; ZnO nanowire; gold nanoparticles

\section{INTRODUCTION (HEADING 1)}

Hydrogen is the lightest and most abundant chemical element in the universe. $\mathrm{H}_{2}$ gas is odorless, colorless, highly reactive and highly flammable with a wide flammable range $(5-75 \%)[1,2]$. Currently, the two largest uses of hydrogen are fossil fuel processing, ammonia production for fertilizer and as clean energy source, being by 3-times more energy dense by mass than gasoline (143 MJ/kg vs $46.9 \mathrm{MJ} / \mathrm{kg}$ ) [3]. Since the 2007 discovery that molecular hydrogen has selective antioxidant properties, multiple studies have shown that $\mathrm{H}_{2}$ has beneficial effects in diverse animal models and human disease, and can be also used as a preventive and therapeutic medical gas for various diseases [4]. $\mathrm{H}_{2}$ have several advantages over current pharmacological therapies: (i) high diffusivity which allows to reach subcellular compartments; (ii) selective reduction of detrimental hydroxyl radicals and peroxynitrite, without decrease of the steady-state levels of nitric oxide; (iii) hydrogen treatment did not eliminate $\mathrm{O}_{2}^{-}$or $\mathrm{H}_{2} \mathrm{O}_{2}$ when tested in vitro $[3,5]$. In gaseous phase the $\mathrm{H}_{2}$ can be easily inhaled using a ventilator circuit, face-mask or nasal cannula [3].

Since 2007 the number of publications on the biologically or medically beneficial effects of $\mathrm{H}_{2}$ is still growing and are mainly focused on tissue dysfunctions, reproductive, urinary, respiratory, digestive, cardiovascular and central nervous systems, metabolic syndrome, etc. [4]. Along with the therapeutic applications, the measurement of breath hydrogen has also attracted a great attention in recent years [6]. Hydrogen in the human body is eliminated through three pathways: flatus, respiratory excretion after absorption into the systemic circulation and metabolism by colonic microbiota (through three metabolic methods) [3].

Despite the fact that the potential of clinical breath analysis has been recognized for centuries, it still remains in its infancy [7]. Breath analysis can be used to detect disease, monitor disease progression, or monitor therapy [7]. The main advantages of breath analysis are: (i) method is noninvasive; (ii) sampling procedure is safe and fast; (iii) does not require any additional apparatus and the subjects are only requested to deeply breathe into the collecting system [8].

In the case of preventive and therapeutic medical applications the safety is a primary concern with respect to $\mathrm{H}_{2}$ transportation, storage, and administration [4]. Therefore, due to the dangerous character of $\mathrm{H}_{2}$ gas and because it cannot be detected by human beings it is important to elaborate the devices for rapid and accurate $\mathrm{H}_{2}$ gas detection even to small concentrations (in range of ppm) [2].

In this context, metal oxide structures are ideal candidates for gas sensing applications due to their advantages such as: (i) low cost; (ii) detection of a wide range of reducing and oxidizing gases and VOCs vapors; (iii) high sensitivity; (iv) possibility to fabricate portable devices [9-11]. For example, recently the highly selective room temperature hydrogen gas sensor was elaborated based on $\mathrm{ZnO}$ columnar films doped with $\mathrm{Pd}$ and decorated with $\mathrm{PdO}_{2} / \mathrm{PdO}$ nanoparticles [12]. Among all types of structures, the quasi-one-dimensional (1-D) structures, such as nanowires, nanobelts, nanorods, etc., have attracted a great attention due their high surface-to-volume ratio, which makes them highly sensitive to surface reactions 
[1]. Exhaled breath contains thousands of endogenous VOC in low concentration ranging from $\mathrm{ppb}$ to $\mathrm{ppm}$ [13]. A recent review identified 1764 human related VOC, 874 of which are found in exhaled breath [14]. Therefore, it is very important to develop the highly selective $\mathrm{H}_{2}$ gas sensors with no crosssensitivity to VOCs vapors.

In this work, the individual Au-NPs/ZnO nanowires were integrated into gas sensing devices using a dual beam FIB/SEM system. The room temperature investigations of gas sensing properties demonstrated high sensitivity and the excellent selectivity to $\mathrm{H}_{2}$ gas compared to VOCs vapors, such as ethanol, acetone, $n$-butanol and 2-propanol, as well as $\mathrm{CO}_{2}$ and $\mathrm{NH}_{3}$ gases. The presented results are of high interest for monitoring of $\mathrm{H}_{2}$ gas level in different applications, including health care applications and clinical breath analysis.

\section{EXPERIMENTAL PART}

The Au-NPs/ZnO NW arrays were grown on glass sheet substrates coated with polycrystalline F-doped $\mathrm{SnO}_{2}$ (FTO, resistance of $10 \Omega / \square$ ) by electrochemical deposition in a classical three-electrode electrochemical cell [15-17]. In this study, only the samples grown using $0.3 \mu \mathrm{M}$ of $\mathrm{HAuCl}_{4}$ (Sigma-Aldrich, > 99.9\%) in an electrochemical bath were used for nanosensor fabrication. More details on synthesis of AuNPs/ZnO NW arrays are presented in previous works [1517]. The detailed morphological, structural, optical and chemical characterization of AuNPs/ZnO NW arrays are presented in previous work [15].

The devices based on individual $\mathrm{ZnO}: \mathrm{Au} \mathrm{NWs}$ were fabricated in a dual beam FIB/SEM scientific instrument, using the method developed by Lupan et al. [1, 18]. The gas sensing measurements were performed at room temperature (RT, $\sim 25$ ${ }^{\circ} \mathrm{C}$ ) in normal ambient air (relative humidity of $30-40 \%$ ). The gas response $(S)$ was measured as ratio of device current under exposure to tested gases and VOCs $\left(I_{\mathrm{gas}}\right)$ and under exposure to ambient air $\left(I_{\text {air }}\right)$. The response $\left(t_{\mathrm{r}}\right)$ and recovery $\left(t_{\mathrm{d}}\right)$ times were defined as necessary time to reach and recover $90 \%$ of full response. The electrical measurements were continuously monitored using a computer-controlled Keithley 2400 source meter using LabView software (National Instruments).

\section{RESULTS}

Figure 1 shows SEM images at different magnifications of AuNPs/ZnO nanowire arrays grown using $0.3 \mu \mathrm{M}$ of $\mathrm{HAuCl}_{4}$ in the electrolyte solution. From Figure 1a can be observed that samples are composed of fairly uniformly distributed nanowires on the substrate, which are oriented upward with respect to the FTO film underlying glass substrate. The NWs diameters vary in the range of $100-200 \mathrm{~nm}$ (see Figure 1b,c). It was observed that NWs are tilted from the vertical direction with increased surface texture. From Figure $\mathbf{1 b}$ and $\mathbf{1 c}$ it can be clearly observed that on the surface of $\mathrm{ZnO} \mathrm{NWs}$ the nanoparticles with different diameters $(10-30 \mathrm{~nm})$ are attached. The origin of these nanoparticles was investigated in previous work using transmission electron microscopy, selected area electron diffractions patterns and energydispersive X-ray (EDX) spectroscopy [15], and was demonstrated that these NPs are composed of $f c c$ gold, with $d\left(\begin{array}{lll}1 & 1 & 1\end{array}\right)=0.231 \mathrm{~nm}, d\left(\begin{array}{lll}0 & 0 & 2\end{array}\right)=0.201 \mathrm{~nm}$ and with Fm-3m space group. The deposition of Au NPs on the surface of $\mathrm{ZnO}$ NWs can be described by the following equation [15]:

$$
\mathrm{AuCl}_{4}^{-}+3 e^{-} \leftrightarrow A u^{0}+4 \mathrm{Cl}^{-}
$$

No evidence of $\mathrm{ZnO}$ NWs doping with $\mathrm{Au}$ was observed, which can be a result of low solubility of $\mathrm{Au}$ in $\mathrm{ZnO}$ [15]. The performed high resolution X-ray photoelectron spectroscopy measurements of $\mathrm{Au}-4 \mathrm{~d}$ core level demonstrated that $\mathrm{Au}$ is present in metallic form and no oxidation was observed.

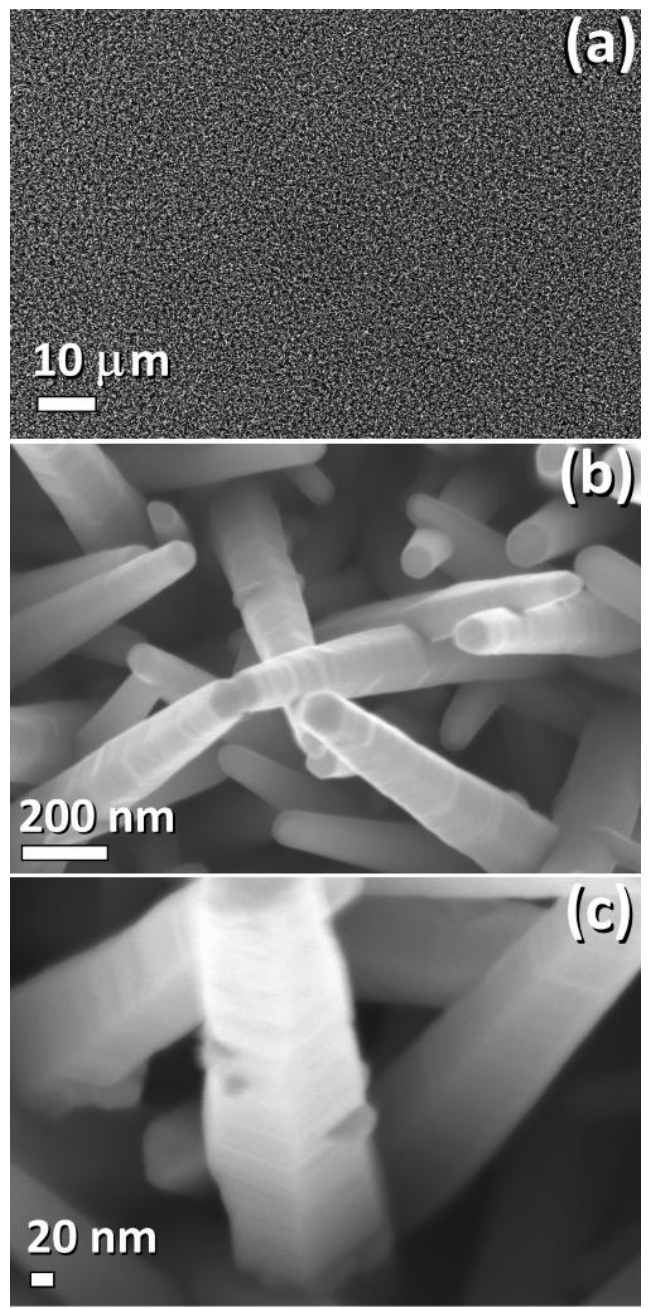

Fig. 1. SEM images of Au-NPs/ZnO nanowire arrays at different magnifications: (a) low; (b) medium; (c) high.

Figure 2a shows SEM image of the integrated individual AuNPs/ZnO nanowire, which was contacted to $\mathrm{Au} / \mathrm{Cr}$ pads on the chip using $\mathrm{Pt}$ complex. The chip represents a $\mathrm{SiO}_{2}$-coated Si substrate $(10 \mathrm{~mm} \times 10 \mathrm{~mm})$ with preliminary deposited $\mathrm{Au} / \mathrm{Cr}$ contacts as external electrodes. More information on chip can be found in our previous work [16]. On one chip can be integrated a maximum of 8 individual nanowires, which is very important for further developments of multi-sensor systems, such as "electronic nose" in order to discriminate complex mixtures of gases and VOCs. In our case, the diameter 
of AuNPs/ZnO nanowire is $\sim 150 \mathrm{~nm}$, while the length between $\mathrm{Pt}$ contacts is $\sim 2 \mu \mathrm{m}$. The current - voltage characteristic of device, measured at room temperature in a relatively wide range of $-5 \mathrm{~V}$ to $+5 \mathrm{~V}$ is presented in Figure $\mathbf{2 b}$, showing the formation of double-Schottky contacts due to higher work function of $\mathrm{Pt}$ compared to electron affinity of $\mathrm{ZnO}[1]$.
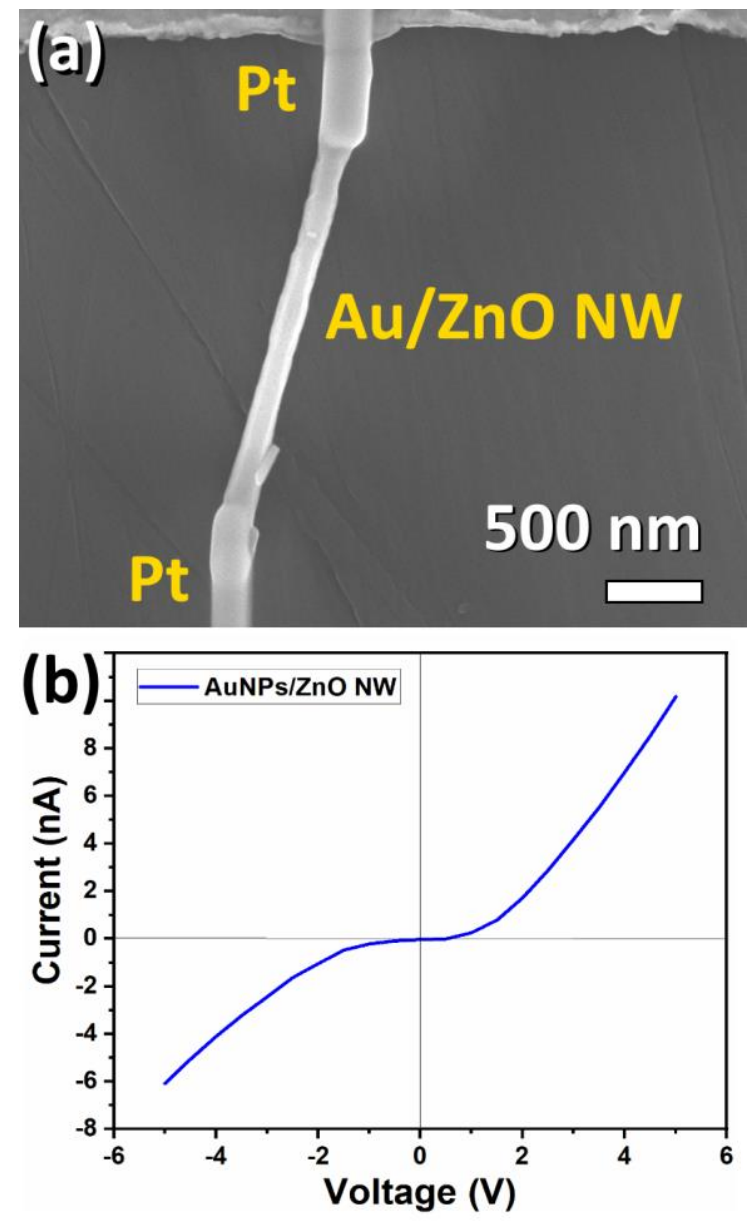

Fig. 2. (b) SEM image of device based on individual AuNPs/ZnO nanowire. (b) Current - voltage characteristic of device.

The schematic illustration of $\mathrm{H}_{2}$ gas detection in exhaled breath using an individual $\mathrm{Au}-\mathrm{NPs} / \mathrm{ZnO} \mathrm{NW}$ is presented in Figure 3. According to this method, the elaborated device need to selectively detect the $\mathrm{H}_{2}$ gas among other types of gases such as $\mathrm{CO}_{2}, \mathrm{CO}$ and $\mathrm{NH}_{3}$ and a big variety of VOCs vapors, such as ethanol, acetone, 2-propanol and n-butanol, which are also present in exhaled breath. The direct measurement of exhaled breath cannot be used due to contamination from ambient air and interference from other molecules [7]. Therefore, the exhaled breath needs to be collected in a special sealed container where is placed the sensor unit, for a better accuracy of measurements.

The fabricated device was measured to $100 \mathrm{ppm}$ of $\mathrm{H}_{2}$ gas and a much higher concentration of $1000 \mathrm{ppm}$ for other gases and VOCs vapors. The obtained results are presented in Figure 4a, which demonstrates the high selectivity of $\mathrm{Au}-\mathrm{NPs} / \mathrm{ZnO}$
$\mathrm{NW}$ to $\mathrm{H}_{2}$ gas. No response to $\mathrm{CO}_{2}, \mathrm{CO}, \mathrm{NH}_{3}$, ethanol, acetone, 2-propanol and n-butanol with much higher concentration was observed. The gas response to $100 \mathrm{ppm}$ of $\mathrm{H}_{2}$ gas at room temperature is $\sim 3$. The dynamic response of the device is presented in Figure 4b. As can be observed, even at room temperature operation the response is reversible. The calculated response and recovery times are $\sim 50 \mathrm{~s}$ and $\sim 700 \mathrm{~s}$, respectively.

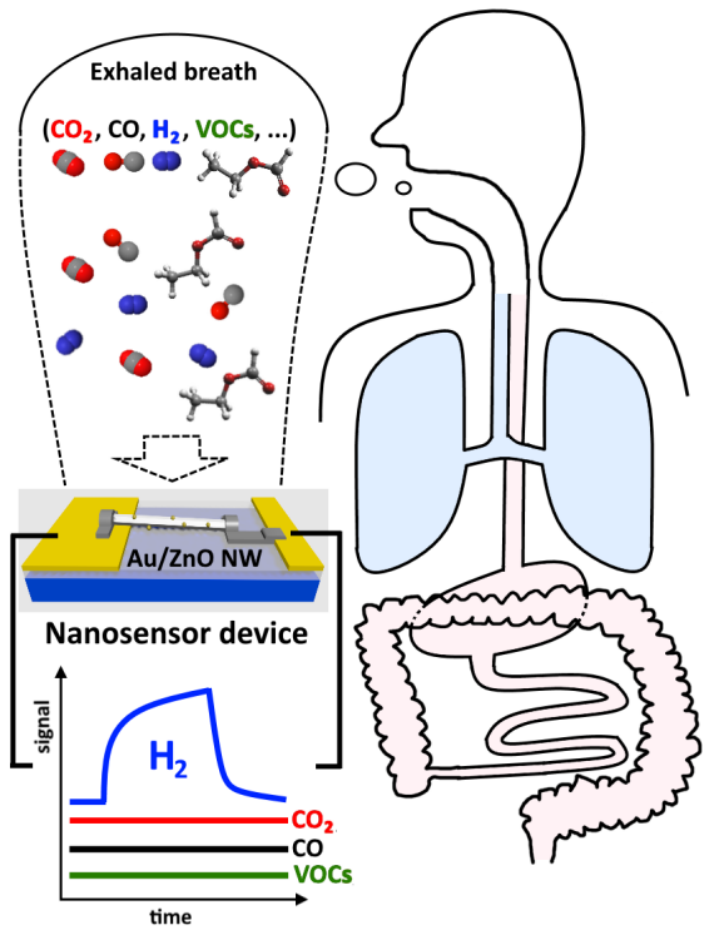

Fig. 3. Schematic illustration of $\mathrm{H}_{2}$ gas detection in exhaled breath using a individual AuNPs/ZnO. 

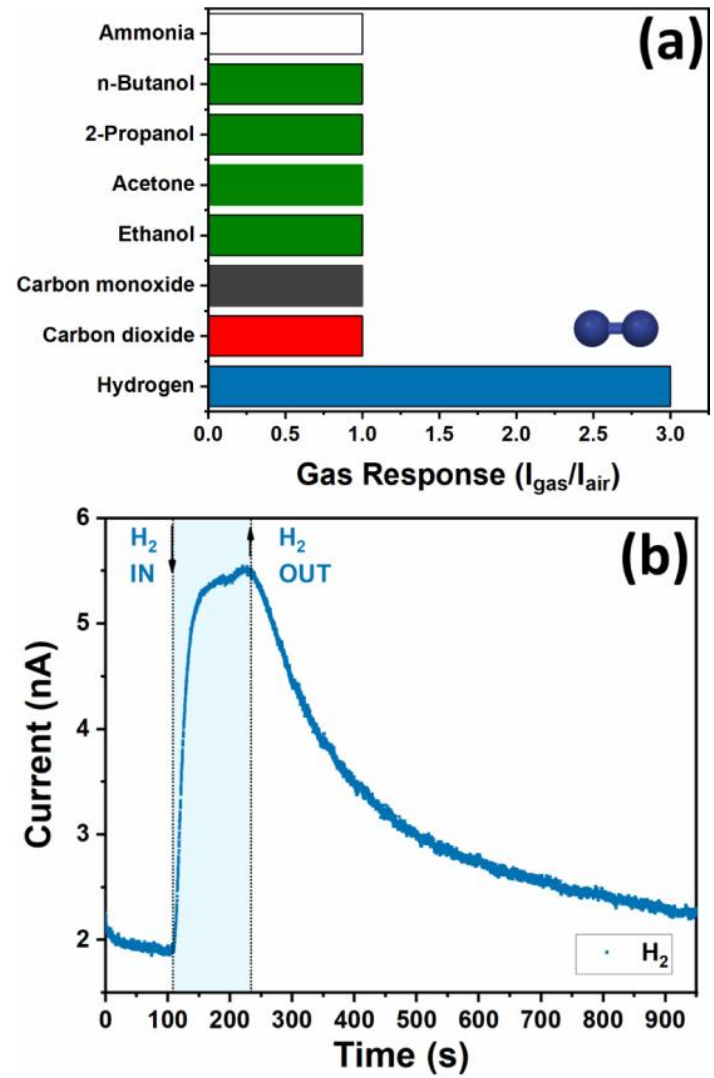

Fig. 4. (a) Gas response of the Au-NPs/ZnO NW to different gases and VOCs vapors. (b) Dynamic gas response to $100 \mathrm{ppm}$ of $\mathrm{H}_{2}$.

\section{CONCLUSIONS}

In this study, the nanosensor based on a singleAu$\mathrm{NPs} / \mathrm{ZnO} \mathrm{NW}$ with a diameter of $\sim 150 \mathrm{~nm}$ and length of $\sim 2 \mu \mathrm{m}$ was successfully fabricated using FIB/SEM equipment. The investigation of gas sensingproperties, measuredat room temperature showed the high response and selectivity ofthe device to $100 \mathrm{ppm}$ of hydrogen gas compared to other widely exhaled gases and VOCs vapors, such as carbon monoxide, carbon dioxide, ammonia, ethanol, n-butanol, 2-propanol and acetone. The obtained nanosensor can be further implemented into different devices for ambient monitoring of $\mathrm{H} 2, \mathrm{H}_{2}$ level monitoring in medical systems for health care applications, as well as in clinical breath analysis for early detection of different diseases.

\section{ACKNOWLEDGMENT}

Dr. Lupan gratefully acknowledges PSL University, ChimieParisTech for invited professor positions in 2018 and 2019 and the CNRS Council for support as expert scientist at IRCP Chimie ParisTech, Paris. This research was funded partially by the German Research Foundation (DFG) under the schemes FOR 2093 (AD 183/12-2). Katrin Brandenburg is acknowledged for her help in the proof-reading of the manuscript. This research was partly supported by the Technical University of Moldova.

\section{REFERENCES}

[1] O. Lupan, V. Cretu, V. Postica, M. Ahmadi, B.R. Cuenya, L. Chow, et al., "Silver-doped zinc oxide single nanowire multifunctional nanosensor with a significant enhancement in response", Sensors and Actuators B, 223, 2016, pp. 893-903.

[2] M. Hoppe, O. Lupan, V. Postica, N. Wolff, V. Duppel, L. Kienle, et al., " $\mathrm{ZnAl}_{2} \mathrm{O}_{4}$-Functionalized Zinc Oxide Microstructures for Highly Selective Hydrogen Gas Sensing Applications", Physica Status Solidi (a), 215, 2018, pp. 1700772.

[3] C.-S. Huang, T. Kawamura, Y. Toyoda, A. Nakao, "Recent advances in hydrogen research as a therapeutic medical gas, Free Radical Research, 44, 2010, pp. 971-982.

[4] L. Ge, M. Yang, N.-N. Yang, X.-X. Yin, W.-G. Song, "Molecular hydrogen: a preventive and therapeutic medical gas for various diseases", Oncotarget, 8, 2017, pp. 102653.

[5] I. Ohsawa, M. Ishikawa, K. Takahashi, M. Watanabe, K. Nishimaki, K. Yamagata, et al., "Hydrogen acts as a therapeutic antioxidant by selectively reducing cytotoxic oxygen radicals", Nature Medicine, 13, 2007, pp. 688-694.

[6] W. Shin, "Medical applications of breath hydrogen measurements", Analytical and Bioanalytical Chemistry, 406, 2014, pp. 3931-3939.

[7] T.H. Risby, S.F. Solga, "Current status of clinical breath analysis", Applied Physics B, 85, 2006, pp. 421-426.

[8] C. Di Natale, R. Paolesse, E. Martinelli, R. Capuano, "Solid-state gas sensors for breath analysis: A review", Analytica Chimica Acta, 824, 2014, pp. 1-17.

[9] W. Hu, L. Wan, Y. Jian, C. Ren, K. Jin, X. Su, et al., "Electronic Noses: From Advanced Materials to Sensors Aided with Data Processing", Advanced Materials Technologies, 4, 2019, pp. 1800488.

[10] Y.K. Mishra, R. Adelung, "ZnO tetrapod materials for functional applications", Materials Today, 21, 2018, pp. 631-651.

[11] A. Moezzi, A.M. McDonagh, M.B. Cortie, "Zinc oxide particles: Synthesis, properties and applications", Chemical Engineering Journal, 185186, 2012, pp. 1-22.

[12] O. Lupan, V. Postica, M. Hoppe, N. Wolff, O. Polonskyi, T. Pauporté, et al., " $\mathrm{PdO} / \mathrm{PdO}_{2}$ functionalized $\mathrm{ZnO}: \mathrm{Pd}$ films for lower operating temperature $\mathrm{H}_{2}$ gas sensing", Nanoscale, 10, 2018, pp. 14107-14127.

[13] W. Filipiak, V. Ruzsanyi, P. Mochalski, A. Filipiak, A. Bajtarevic, C. Ager, et al., "Dependence of exhaled breath composition on exogenous factors, smoking habits and exposure to air pollutants", Journal of Breath Research, 6, 2012, pp. 036008.

[14] B. de Lacy Costello, A. Amann, H. Al-Kateb, C. Flynn, W. Filipiak, T. Khalid, et al., "A review of the volatiles from the healthy human body", Jorunal of Breath Research, 8, 2014, pp. 014001.

[15] O. Lupan, V. Postica, N. Wolff, J. Su, F. Labat, I. Ciofini, et al., "LowTemperature Solution Synthesis of Au-Modified ZnO Nanowires for Highly Efficient Hydrogen Nanosensors", ACS Appl Mater Interfaces, 11, 2019, pp. 32115-32126.

[16] O. Lupan, V. Postica, T. Pauporté, B. Viana, M.-I. Terasa, R. Adelung, "Room temperature gas nanosensors based on individual and multiple networked Au-modified $\mathrm{ZnO}$ nanowires", Sensors and Actuators B, 299, 2019, pp. 126977.

[17] O. Lupan, V. Postica, T. Pauporté, M. Hoppe, R. Adelung, "UV nanophotodetectors: A case study of individual Au-modified $\mathrm{ZnO}$ nanowires", Sensors and Actuators A, 296, 2019, pp. 400-408.

[18] O. Lupan, L. Chow, T. Pauporté, L.K. Ono, B. Roldan Cuenya, G. Chai, "Highly sensitive and selective hydrogen single-nanowire nanosensor", Sensors and Actuators B, 173, 2012, pp. 772-780. 